\title{
KEBUTUHAN LUAS AREA INDUSTRI PENGOLAHAN KOMBINASI BUAH MASA PANDEMI COVID-19
}

(The need for the area of fruit combination processing industry pandemy time covid-19)

\section{Salfiana}

Universitas Muhammadiyah Sidenreng Rappang, Program Studi Teknologi Hasil Pertanian Jln. Angk. 45 No.1 A Lt. Salo Rappang - Sidrap - Sul-Sel Kode Pos 91651

Email: salfiana.husain@umsrappang.ac.id

\begin{abstract}
ABSTRAK
Tujuan penelitian ini adalah menghitung kebutuhan luas area industri pengolahan kombinasi buah masa pademi covid-19. Perhitungan dilakukan dengan memperhatikan protokol kesehatan, physical distanching dalam semua aktifitas bekerja. Pengaturan jarak antar pekerja minimal jarak 1 meter. Hasil penelitian menunjukkan bahwa teori perancangan tata letak atau penentuan kebutuhan luas area industri pengolahan kombinasi buah sesuai dengan masa pademi covid-19. Teori perancangan yang ada, memungkinkan tiap pekerja melakukan physical distanching. Kebutuhan luas area industri pengolahan kombinasi buah masa pademi covid-19 diperoleh hasil sama saja dengan masa normal yaitu $59,38 \mathrm{~m}^{2}$.
\end{abstract}

Kata Kunci: Luas area; industri; buah; masa pademi; covid-19

\begin{abstract}
The research aimed to calculate the area required for the fruit combination processing industry during the Covid-19 time. The calculation is done by paying attention to the health protocol, physical distancing in all work activities. The minimum distance between workers is 1 meter. The results showed that the theory of the layout design or determination of the fruit combination processing industry's area requirements was in accordance with the covid19 period. The existing design theory allows each worker to do physical distancing. The need for an area for the fruit combination processing industry during the Covid-19 time resulted in the same results as the average period is $59.38 \mathrm{~m}^{2}$.
\end{abstract}

Keywords: Area; industry; fruit; pademi time; covid-19

\section{PENDAHULUAN}

Kebutuhan luas area industri

pengolahan buah merupakan bagian dari perancangan tata letak fasilitas produksi.

Perancangan tata letak berhubungan dengan penyusunan mesin, peralatan produksi serta ruangan dalam industri agar proses produksi dapat berjalan dengan efektif dan efisien (Hadiguna dan Setiawan, 2008). Tata letak menyusun segala sesuatu yang diperlukan untuk proses produksi (Abraham dan Sasikumar, 2013).

Luas area yang dimaksudkan disini adalah kebutuhan luas lantai untuk setiap tempat kerja. Untuk memudahkan, umumnya dipilih segi empat. Ruang yang dibutuhkan oleh fasilitas berkaitan dengan peralatan, bahan, pegawai, dan kegiatan. Menurut (Apple, 1990) Penentuan kebutuhan luas area ini, diperlukan penambahan kelonggaran $40 \%$ sampai 
$60 \%$ untuk gang (aisle) dan operator.

Selain itu untuk tiap mesin atau fasilitas pendukung digunakan teloransi 0,50-1 meter pada setiap sisi mesin.

Namun, di Tahun 2019 terjadi pademi covid-19 yang melanda dunia. Hal ini berpengaruh pada berbagai sektor, seperti sektor industri. Diperlukan langkah-langkah untuk mencegah dan mengendalikan potensi penularan COVID19 di lingkungan kerja yang dilaksanakan oleh seluruh komponen yang ada di tempat kerja mulai dari pekerja hingga tingkat pimpinan serta memberdayakan semua sumber daya yang ada.

Aktifitas kerja pun berubah pada masa pademi ini, pekerja di himbau melakukan physical distanching dalam semua aktifitas bekerja. Pengaturan jarak antar pekerja minimal jarak 1 meter pada setiap aktivitas kerja, pengaturan meja kerja, fasilitas dan lainnya (Kesehatan RI, 2020).

Penentuan pengaturan jarak 1 meter ini menimbulkan pertanyaan apakah berpengaruh terhadap kebutuhan luas area dalam industri. Untuk itu, penelitian ini bertujuan menghitung kebutuhan luas area industri pengolahan industri buah Masa pademi covid-19.

\section{METODE PENELITIAN}

Penelitian ini dilaksanakan dengan melakukan pengumpulan data berupa data primer dan sekunder. Baik yang bersifat kuantitatif maupun kualitatif. Aktivitas dan metode penelitian yang dilakukan di sajiakan pada tabel berikut.

Tabel 1. Aktivitas dan metode yang digunakan.

\begin{tabular}{|c|c|c|}
\hline No & Aktivitas & Metode \\
\hline 1. & $\begin{array}{l}\text { Pengumpulan data } \\
\text { sekunder }\end{array}$ & $\begin{array}{l}\text { Pengambilan } \\
\text { Data } \\
\text { Penelitian } \\
\text { yang telah } \\
\text { dilakukan }\end{array}$ \\
\hline 2. & $\begin{array}{l}\text { Mengidentifikasi } \\
\text { aktivitas-aktivitas yang } \\
\text { telah didefenisikan } \\
\text { sebagai fasilitas- } \\
\text { fasilitas industri. }\end{array}$ & \\
\hline 3 & $\begin{array}{l}\text { Mendapatkan data } \\
\text { kebutuhan luas area } \\
\text { produksi masa normal } \\
\text { (sebelum pandemi } \\
\text { covid-19) }\end{array}$ & \\
\hline 4 & $\begin{array}{c}\text { Menentukan data } \\
\text { kebutuhan luas area } \\
\text { produksi masa pademi } \\
\text { covid-19. }\end{array}$ & $\begin{array}{c}\text { Teknik } \\
\text { Konvensional }\end{array}$ \\
\hline 7 & $\begin{array}{l}\text { Menyusun Activity } \\
\text { Relationship Diagram } \\
\text { (ARD) berdasarkan } \\
\text { tingkat hubungan. }\end{array}$ & \\
\hline 8 & $\begin{array}{l}\text { Menyiapkan Area } \\
\text { Template berdasarkan } \\
\text { kebutuhan luas lantai } \\
\text { setiap fasilitas. }\end{array}$ & \\
\hline 9 & $\begin{array}{l}\text { Membuat Area } \\
\text { Allocating Diagram } \\
\text { (AAD) sebagai tata } \\
\text { letak akhir rancangan. }\end{array}$ & \\
\hline
\end{tabular}




\section{HASIL DAN PEMBAHASAN}

Hasil perancangan industri pengolahan kombinasi buah masa normal disajikan pada Tabel 1 (Terlampir) dengan total luas area yang dibutuhkan 59,38 $\mathrm{m}^{2}$ (Salfiana, 2015). Sedangkan kebutuhan luas area industri pengolahan buah masa pademi covid-19 ternyata diperoleh hasil sama saja dengan masa normal yaitu 59,38 $\mathrm{m}^{2}$.

Adanya persamaan hasil ini disadari dari pendapat (Apple, 1990) bahwa Penentuan kebutuhan luas area ini, diperlukan penambahan kelonggaran $40 \%$ sampai $60 \%$ untuk gang (aisle) dan operator. Selain itu untuk tiap mesin atau fasilitas pendukung digunakan teloransi 0,50-1 meter pada setiap sisi mesin. Hal ini, ternyata sudah sangat sesuai dengan protokol kesehatan (Kesehatan RI, 2020) bahwa dalam melakukan physical distanching pengaturan jarak antar pekerja minimal jarak 1 meter pada setiap aktivitas kerja, pengaturan meja kerja, fasilitas dan lainnya.

Perancangan tata letak akan terhidar dari bahaya dan mengurangi kecelakaan. Hal ini di dukung oleh pendapat (Singh, 2012), bahwa merancang tata letak akan memberikan praktek manajemen operasi yang efisien dengan mengurangi kecelakaan, bahaya, dengan meningkatkan kemudahan \& kenyamanan.
Proses perancangan dimulai dengan menganalisis tingkat hubungan menggunakan ARC (Activity Relationship Chart) atau peta hubungan kerja kegiatan dalam industri. Hubungan ARC yang telah dibuat akan berdampak pada pergerakan dalam industri tersebut, sehingga physical distanching akan tetap bisa dipatuhi setiap pekerja.

Rancangan Area Allocating Diagram (AAD) merupakan tata letak akhir industri pengolahan kombinasi buah. Pada AAD, diperoleh pula bentuk umum aliran bahan. Pada perancangan industri puree, sari buah \& selai pola aliran bahan yang diterapkan yaitu pola aliran bentuk U (Salfiana, 2015). Hal ini sesuai pula dengan pendapat (Hadiguna \& Setiawan, 2008), bahwa keterbatasan lantai yang tersedia dapat diantisipasi dengan pola aliran bentuk U. Pola aliran bentuk U akan diterapkan jika akhir proses produksi akan berada pada lokasi yang sama dengan awal proses produksinya karena keadaan fasilitas transportasi maupun pemakaian mesin bersama. 


\section{LAMPIRAN}

Tabel 1. Jumlah kebutuhan luas area industri buah masa normal

\begin{tabular}{|c|c|c|c|c|c|c|}
\hline Departemen & Jenis Kebutuhan & $\begin{array}{l}\text { Jumlah } \\
\text { satuan }\end{array}$ & $\begin{array}{l}\text { Dimensi } \\
(\mathbf{m x m})\end{array}$ & $\begin{array}{c}\text { Luas } \\
\left(\mathrm{m}^{2}\right)\end{array}$ & $\begin{array}{c}\text { Kelonggaran } \\
(150 \%)\end{array}$ & $\begin{array}{c}\text { Sub Total } \\
\left(\mathbf{m}^{2}\right)\end{array}$ \\
\hline \multirow[t]{7}{*}{ Bahan Baku } & Rak Bahan Baku & 1 & $1,00 \times 1,00$ & 1,00 & 1,50 & \multirow{7}{*}{5,66} \\
\hline & Tempat Gula & 1 & $1,00 \times 0,50$ & 0,50 & 0,75 & \\
\hline & Bahan tambahan & $\&$ & $1,00 \times 0,50$ & 0,50 & 0,75 & \\
\hline & Timbangan Tanita & & & & & \\
\hline & Timbangan Portabel & 1 & $0,45 \times 0,60$ & 0,27 & 0,41 & \\
\hline & Tempat kemasan & 1 & $1,00 \times 1,00$ & 1,00 & 1,50 & \\
\hline & Operator & 1 & $1,00 \times 0,50$ & 2,00 & 0,75 & \\
\hline Trimming/Pra & Meja Kerja & 3 & $1,50 \times 0,75$ & 3,38 & 5,06 & \multirow{3}{*}{7,19} \\
\hline \multirow[t]{2}{*}{ Pengolahan } & Pengupas Pepaya & 1 & $0,76 \times 0,55$ & 0,42 & 0,63 & \\
\hline & Operator & 2 & $1,00 \times 0,50$ & 1,00 & 1,50 & \\
\hline \multirow[t]{8}{*}{ Pengolahan } & Blender & 1 & $0,30 \times 0,60$ & 0,18 & 0,27 & \multirow{8}{*}{14,28} \\
\hline & Ember & 2 & $0,30 \times 0,50$ & 0,30 & 0,45 & \\
\hline & Mesin pasteurisasi & 1 & $1,15 \times 0,75$ & 0,86 & 1,29 & \\
\hline & Pengaduk selai & 1 & $0,33 \times 0,60$ & 0,20 & 0,30 & \\
\hline & Troli lipat & 1 & $0,48 \times 0,74$ & 0,36 & 0,53 & \\
\hline & Meja kerja & 3 & $1,50 \times 0,75$ & 3,38 & 5,06 & \\
\hline & Instalasi air & 2 & $1,50 \times 0,75$ & 2,25 & 3,38 & \\
\hline & Operator & 4 & $1,00 \times 0,50$ & 2,00 & 3,00 & \\
\hline Kantor \& & Meja Kerja & 1 & $1,00 \times 1,00$ & 1,00 & 1,50 & \multirow{6}{*}{8,79} \\
\hline Penyimpanan & Kursi & 1 & $0,60 \times 0,60$ & 0,36 & 0.54 & \\
\hline \multirow[t]{4}{*}{ Produk Jadi } & Rak 1 & 1 & $3,00 \times 0,50$ & 1,50 & 2,25 & \\
\hline & Rak 2 & 1 & $2,00 \times 0,50$ & 1,00 & 1,50 & \\
\hline & Rak 3 & 1 & $2,00 \times 0,50$ & 1,00 & 1,50 & \\
\hline & Operator & 2 & $1,00 \times 0,50$ & 1,00 & 1,50 & \\
\hline Pengujian & Meja Kerja & 1 & $1,00 \times 1,00$ & 1,00 & 1,50 & \multirow{3}{*}{2,25} \\
\hline Mutu & Operator & 1 & $1,00 \times 0,50$ & 0,50 & 0,75 & \\
\hline Tempat & Loker & 1 & $0,50 \times 1,00$ & 0,50 & 0,75 & \\
\hline \multirow[t]{2}{*}{ Istirahat } & $\mathrm{WC}$ & 1 & $1,50 \times 1,00$ & 1,50 & 2,25 & \multirow[t]{2}{*}{5,25} \\
\hline & Operator & 3 & $1,00 \times 0,50$ & 1,50 & 2,25 & \\
\hline \multirow{2}{*}{ Limbah } & Drum & 1 & $0,80 \times 0,80$ & 0,64 & 0,96 & \multirow{2}{*}{1,71} \\
\hline & Operator & 1 & $1,00 \times 0,50$ & 0,50 & 0,75 & \\
\hline Lapangan/ & Kendaraan roda empat & 1 & $2,00 \times 4,00$ & 8,00 & 12,00 & \multirow{3}{*}{14,25} \\
\hline \multirow[t]{2}{*}{ Parkir } & Kendaraan roda dua & 2 & $0,50 \times 1,00$ & 1,00 & 1,50 & \\
\hline & Operator & 1 & $1,00 \times 0,50$ & 0,50 & 0,75 & \\
\hline \multicolumn{6}{|c|}{ Total Luas yang Dibutuhkan } & 59,38 \\
\hline
\end{tabular}

Sumber: Data Sekunder (Salfiana, 2015).

\section{KESIMPULAN}

Kesimpulan pada penelitian adalah teori perancangan tata letak atau penentuan kebutuhan luas area industri pengolahan kombinasi buah sesuai dengan masa pademi covid-19. Teori perancangan yang ada, memungkinkan tiap pekerja melakukan physical distanching. Kebutuhan luas area industri pengolahan kombinasi buah masa pademi covid-19 ternyata diperoleh hasil sama saja dengan masa normal yaitu $59,38 \mathrm{~m}^{2}$.

\section{DAFTAR PUSTAKA}

Abraham, G. E., dan Sasikumar, R. 2013. Layout planning for sustainable development. International Journal of Innovative Research in Science, Engineering \& Technology. Ijirset, 655-665.

Apple, J. M. 1990. Tataletak pabrik dan pemindahan bahan. Edisi Ketiga. Bandung: Penerbit ITB. 
Hadiguna, R. A., \& Setiawan, H. 2008.

Tata Letak Pabrik. Yogyakarta:

Penerbit Andi.

Kesehatan RI, K. M. 2020. Pedoman dan pencegahan

Covid-

19.https://covid19.go.id/storage/ap

p/media/Regulasi/KMK\%20No.\%2

0HK.01.07-MENKES-413-

2020\%20ttg\%20Pedoman\%20Penc egahan $\% 20$ dan $\% 20$ Pengendalian $\%$ 20COVID-19.pdf. Retrieved Juli 21, 2020,

Salfiana, M. B. 2015. Perancangan tata letak fasilitas industri puree, sari buah dan selai dengan kombinasi bahan baku aneka buah. Makassar: Pasca Unhas.

Singh, M. 2012. Innovetive practices in facility layout planning. International Journal of Marketing, Financial Services \& Management Research, 126-139. 